\title{
An Efficient Approach for RNA Extraction from Boar Sperm and Seminal Plasma
}

Vanmathy R. Kasimanickam and Ramanathan K. Kasimanickam

Veterinary Clinical Sciences Department, Washington State University, Pullman, USA

*For correspondence: vkasiman@wsu.edu

[Abstract] Despite transcriptional silencing in mature sperm and cytoplasmic expulsion of RNA during the final sperm maturation process, thousands of RNAs have been successfully identified in ejaculated sperm. Although most of RNAs' function is still unknown, it is suggested that sperm RNAs have a vital biological role in fertilization and post-fertilization events. Nevertheless, the lack of accurate RNA isolation techniques and the resultant good quality sperm RNA has hampered the exploration of sperm RNAs function. Additionally, small non-coding RNAs are found in extracellular fluids including seminal plasma. These small RNAs may participate in cell to cell communication or intracellular and extracellular message transmission. Developing precise protocols to extract RNA from sperm and seminal plasma is critical to elucidate sperm physiology and paternal contributions to fertilization and post-fertilization events. A detailed procedure consisting of semen collection, separation of sperm and seminal plasma, extracting RNA from sperm and seminal plasma, and determining the quantity and quality of RNA for boar semen is presented here. This efficient protocol can be extrapolated to isolate RNAs from sperm and seminal plasma across mammalian species.

Keywords: Semen collection, RNA extraction, Boar sperm, Seminal plasma, Non-coding RNA, Spincolumn based purification, RNA elution using nuclease free water

[Background] Transcriptionally inactive mature sperm contains a complex population of RNAs including non-coding small RNAs (Ostermeier et al., 2002). These RNAs can participate in fertilization and postfertilization events including zygotic gene activation. Recently, it was suggested that sperm also can pick up small RNAs on their way during the epididymal transit and these small RNAs can influence the gene regulation in developing embryos for efficient implantation (Kasimanickam et al., 2019b). It is important to study the RNA profiles in immature and mature sperm harvested from various locations such as caput epididymis, cauda epididymis, ejaculated sperm and seminal plasma to know how these RNAs are shuttled between sperm cells and seminal plasma. Better understanding of coding and non-coding RNAs in sperm and seminal plasma by gene expression arrays and microarrays allows investigating the problems associated with infertility. Nevertheless, success of microarray and gene expression analyses is extremely dependent on the quality and quantity of the RNA obtained from sperm and seminal plasma. Therefore, the development of methods that isolate highly purified and intact RNA from sperm and seminal plasma is of utmost importance. Purification of sperm and seminal plasma, RNA extraction from sperm and seminal plasma and evaluation of RNA quality are the critical steps to be considered to achieve these goals. Since sperm and seminal plasma contain a very small amount of RNA, a method consisting capture of RNA by silica membrane and elution using nuclease-free water (column-based 
approach) is more advantageous to perform rather than a method involving precipitation of RNA. Hence, detailed protocols for semen collection, semen processing to purify sperm and seminal plasma, RNA isolation from sperm and seminal plasma adopting a column-based approach and determining the quantity and quality of RNA for boars are described here.

\section{Materials and Reagents}

1. Pipette tips (Eppendorf, catalog numbers: 02-717-349, 02-717-351, 02-717-352)

2. Disposable homogenizer (Thermo Fisher Scientific, Fisher, catalog number: 12-141-368)

3. Polyvinyl gloves (Thermo Fisher Scientific, Fisher Scientific, catalog number: 19-121-834B)

4. J-cloth (https://www.amazon.com/J-Cloth-Blue-50s/dp/B00V3UIQ3E)

5. Miracloth (Millipore Sigma, Millipore, catalog number: 475855)

6. Microscopic slides (Thermo Fisher Scientific, Thermo Scientific, catalog number: 4951PLUS4)

7. Microscopic cover glasses (Thermo Fisher Scientific, Thermo Scientific, catalog number: 18X18-1)

8. Graduated measuring cylinder

9. Falcon tubes, $50 \mathrm{ml}$ (Thermo Fisher Scientific, Corning, catalog number: 14-432-22)

10. Microcentrifuge tubes (Thermo Fisher Scientific, Thermo Scientific, catalog number: 3448 )

11. Square cuvette

12. Mature trained boars for semen collection (Landrace boars of 8 to 18 months of age were used in this protocol)

Notes:

a. Follow institutional guidelines for animal maintenance and use for sample collection.

b. Maintain clean semen collection area with appropriate human and animal safety guidelines.

13. Beltsville Thawing Solution (Minitube USA, catalog number: 13525)

14. Liquid nitrogen (Washington State University Store, WSU, catalog number: 12506)

15. RNeasy plus Universal Mini Kit (RNeasy mini spin column, 1.5- and 2.0-ml collection tubes, QIAzol lysis reagent, gDNA eliminator solution, RWT buffer, RPE buffer and RNase free water) (Qiagen Inc., catalog number: 73404)

16. Chloroform (VWR International, J.T. Baker, catalog number: 9180-1)

17. Ethanol (Washington State University Store, Decon, catalog number: Decon 2701)

18. MiRNeasy serum/plasma kit (RNeasy MinElute spin column, 1.5- and 2.0-ml collection tubes, QIAzol lysis reagent, RWT buffer, RPE buffer and RNase free water) (Qiagen Inc., catalog number: 217184)

19. MiRNeasy serum/plasma spike-in-controls (Qiagen Inc., Valencia, CA, USA, catalog number: 219610)

20. Mild disinfectant solution (Washington State University Store, Decon, catalog number: Decon 57065) 


\section{Equipment}

1. Boar semen collection flask (IMV Technologies USA, IMV, catalog number: 017282)

2. Pipettes (Eppendorf, catalog numbers: 2231300034, 2231300037)

3. Adjustable built-in semen collection dummy

4. Phase-contrast microscope (Minitube, Olympus CX43, heated stage, HT 200, catalog number: 12005/0041)

5. Refrigerated centrifuge (Jouan refrigerated centrifuge, model: CR422)

6. Microcentrifuge (Eppendorf, model: $5415 \mathrm{C}$ )

7. Ultra-freezer $\left(-80^{\circ} \mathrm{C}\right)$

8. Spectrophotometer (Thermo Fisher Scientific, model: NanoDrop 1000)

9. Benchtop incubator (Unico, model: Unico 30L Incubator \#L-CU300)

\section{Procedure}

A. Boar semen collection

1. Follow the institutional guidelines to maintain boars and semen collection procedures. Use mature and trained boars for semen collection. Maintain a hygienic environment in semen collection area.

2. Use gloved hand technique to collect boar semen (Kasimanickam et al., 2019b). After mounting on a dummy, clean sheath and prepuce with a mild disinfectant solution. Following a couple of copulatory thrusts, grasp the corkscrew penis with a gloved hand to collect ejaculate.

Note: Use polyvinyl gloves not the latex gloves since the latex gloves are spermicidal in nature.

3. Discard the pre-sperm fraction. Collect the sperm-rich fraction into a pre-warmed container through a j-cloth filter (Thermo Fisher Scientific, Bothell, WA, USA). Maintain clean environment to prevent contamination.

Note: Pre-warm the container, filter cloths, transfer pipets, microscopic slides and coverslips at $37^{\circ} \mathrm{C}$ using a benchtop incubator.

4. Assess the sperm motility immediately after the semen collection. Place a drop of semen on a pre-warmed $\left(37^{\circ} \mathrm{C}\right)$ microscopic slide and observe under a phase contrast microscope at 100x magnification. Use the semen having $\geq 80 \%$ motility for the subsequent procedures (RNA isolation from sperm and seminal plasma).

5. Filter the sperm-rich fraction through a double layered Miracloth (Millipore Sigma, Burlington, MA, USA) into a pre-warmed conical flask to determine the volume, concentration, motility and presence of immature sperm cells (Table 1).

6. Determine the semen volume using a graduated measuring cylinder.

7. Evaluate the sperm concentration using a calibrated and standardized spectrophotometer for boar semen. Pipet the diluted semen sample in $2.9 \%$ sodium citrate in a square cuvette and measure the optical density at the excitation wavelength of $550 \mathrm{~nm}$. Note the sperm 
concentration corresponding to the OD.

Table 1. Semen volume, concentration, motility and purity in ten mature Landrace boars

\begin{tabular}{|l|l|l|l|l|}
\hline $\begin{array}{l}\text { Mature } \\
\text { boars }^{1}\end{array}$ & Semen volume & Sperm \\
moncentration $^{3}$ & $\begin{array}{l}\text { Sperm } \\
\text { motility }^{4}\end{array}$ & $\begin{array}{l}\text { Presence of } \\
\text { immature sperm } \\
\text { \& somatic cells }\end{array}$ \\
\hline Boar 1 & $120 \mathrm{ml}$ & $1.2 \times 10^{9} / \mathrm{ml}$ & $90 \%$ & Absence \\
\hline Boar 2 & $150 \mathrm{ml}$ & $0.8 \times 10^{9} / \mathrm{ml}$ & $85 \%$ & Absence \\
\hline Boar 3 & $120 \mathrm{ml}$ & $1.0 \times 10^{9} / \mathrm{ml}$ & $90 \%$ & Absence \\
\hline Boar 4 & $180 \mathrm{ml}$ & $1.5 \times 10^{9} / \mathrm{ml}$ & $88 \%$ & Absence \\
\hline Boar 5 & $130 \mathrm{ml}$ & $0.9 \times 10^{9} / \mathrm{ml}$ & $90 \%$ & Absence \\
\hline Boar 6 & $180 \mathrm{ml}$ & $1.2 \times 10^{9} / \mathrm{ml}$ & $85 \%$ & Absence \\
\hline Boar 7 & $200 \mathrm{ml}$ & $1.5 \times 10^{9} / \mathrm{ml}$ & $87 \%$ & Absence \\
\hline Boar 8 & $170 \mathrm{ml}$ & $1.0 \times 10^{9} / \mathrm{ml}$ & $85 \%$ & Absence \\
\hline Boar 9 & $150 \mathrm{ml}$ & $1.2 \times 10^{9} / \mathrm{ml}$ & $90 \%$ & Absence \\
\hline Boar 10 & $200 \mathrm{ml}$ & $0.9 \times 10^{9} / \mathrm{ml}$ & $87 \%$ & Absence \\
\hline Mean \pm SD & $160 \pm 30.55 \mathrm{ml}$ & $1.2 \times 10^{9} \pm 0.24 / \mathrm{ml}$ & $87.7 \pm 2.21 \%$ & N/A \\
\hline
\end{tabular}

18 to 18 months Landrace

${ }^{2}$ Sperm-rich fraction

${ }^{3}$ Evaluated by spectrophotometer (Spectronic 20D+ spectrophotometer)

${ }^{4}$ Evaluated using phase-contrast microscope

${ }^{5}$ Evaluated using phase-contrast microscope

B. Separation of sperm and seminal plasma

1. Centrifuge undiluted semen at $1,000 \times \mathrm{g}$ for $20 \mathrm{~min}$ at $4{ }^{\circ} \mathrm{C}$. Use pre-cold $50 \mathrm{ml}$ Falcon tubes for $40 \mathrm{ml}$ semen.

Note: Extended or non-extended semen should be stored at $15{ }^{\circ} \mathrm{C}$ to maintain viability to use for insemination.

2. Transfer the seminal plasma (supernatant) into a new tube. Centrifuge the seminal plasma at $16,000 \times \mathrm{g}, 4^{\circ} \mathrm{C}$ to ensure removal of sperm. Use microcentrifuge tubes to use the centrifugal force of $16,000 \times g$ at $4{ }^{\circ} \mathrm{C}$.

Note: Any other types of centrifuges that can reach higher centrifugal force and the temperature of $4{ }^{\circ} \mathrm{C}$ can also be used to separate seminal plasma from the semen.

3. Aliquot the seminal plasma $\left(250 \mu \mathrm{l}\right.$ aliquots) and store at $-80^{\circ} \mathrm{C}$.

Note: The number of $250 \mu$ aliquots that will be stored can be determined based on your experimental plan.

4. Wash the sperm pellet twice using Beltsville Thawing Solution (BTS; IMV Technologies, Maple Grove, MN, USA) and centrifuging at $1,000 \times g$ for 20 min at $4{ }^{\circ} \mathrm{C}$.

Note: While re-suspending the sperm pellet, dissolve the pellet in a small volume $(1 \mathrm{ml})$ of BTS 
first, and dilute further (20 ml) with BTS for effective washings.

5. Re-suspend the final sperm pellet in BTS $(20 \mathrm{ml}$; resuspend in $1 \mathrm{ml}$ first, add $19 \mathrm{ml}$ and mix the suspension thoroughly) at $4{ }^{\circ} \mathrm{C}$, aliquot in micro centrifuge tubes (approximately $500 \times 10^{6}$ sperm). Centrifuge at $16,000 \times \mathrm{g}, 4^{\circ} \mathrm{C}$ and discard the supernatant. Flash-freeze the sperm pellet in liquid nitrogen and then store at $-80^{\circ} \mathrm{C}$.

Note: Based on the initial concentration, the sperm can be resuspended and aliquoted. For example, when the sample of $40 \mathrm{ml}$ semen contains 40 billion sperm, the final sperm pellet after washing can be resuspended in $20 \mathrm{ml}$. Therefore, an aliquot of $250 \mu \mathrm{l}$ will contain $500 \times 10^{6}$ sperm. Modify your starting volume of semen based on the experimental design and the need.

\section{Sperm RNA purification}

1. Isolate total RNA containing small RNAs including miRNAs from sperm using RNeasy plus Universal Mini Kit (Qiagen Inc., Valencia, CA, USA).

2. Add $900 \mu \mathrm{l}$ QIAzol lysis reagent to the sperm pellet (approximately $500 \times 10^{6}$ sperm). homogenize completely using a disposable homogenizer (Thermo Fisher Scientific, San Francisco, CA, USA), and hold at room temperature for $5 \mathrm{~min}$ to promote dissociation of nucleoprotein complexes.

3. Add $100 \mu \mathrm{l}$ genomic DNA (gDNA) eliminator solution and shake the mixture vigorously to eliminate gDNA.

4. Add $180 \mu \mathrm{l}$ of chloroform. Agitate vigorously for about $1 \mathrm{~min}$ and incubate for $2-3 \mathrm{~min}$ at room temperature.

5. Centrifuge the mixture at $12,000 \times \mathrm{g}$ for $15 \mathrm{~min}$ at $4{ }^{\circ} \mathrm{C}$. Harvest the upper aqueous phase $(\sim 600 \mu \mathrm{l})$ into a new Eppendorf tube, add 1.5 volume of $100 \%$ ethanol, and mix the mixture thoroughly by pipetting up and down.

6. Layer the sample (about $700 \mu \mathrm{l}$ ) on an RNeasy mini spin column (included in the RNeasy plus Universal Mini Kit), and centrifuge at $\geq 8,000 \times g$ for $30 \mathrm{~s}$ at room temperature.

7. Discard the flow-through and repeat the centrifugation with the rest of the sample. Discard the flow-through again.

8. Wash the bound RNA by centrifugation ( $\geq 8,000 \times g, 30 \mathrm{~s}$, at room temperature) using buffers RWT and RPE consequently.

9. Add $700 \mu \mathrm{l}$ buffer RWT to the RNeasy spin column. Close the lid gently, and centrifuge for $30 \mathrm{~s}$ at $\geq 8,000 \times g$ to wash the membrane. Discard the flow-through.

Note: Dilute the RWT buffer by adding 2 volumes of ethanol (96-100\%) before use.

10. Add $500 \mu \mathrm{l}$ RPE buffer to the RNeasy spin column. Close the lid gently, and centrifuge for $30 \mathrm{~s}$ at $\geq 8,000 \times g$ to wash the membrane. Discard the flow-through.

Note: Dilute the RPE buffer by adding 4 volumes of ethanol (96-100\%) before use.

11. Repeat the RPE wash by centrifuging for $2 \mathrm{~min}$.

12. Place the RNeasy spin column in a new $2 \mathrm{ml}$ collection tube. Close the lid gently, and centrifuge at full speed for $1 \mathrm{~min}$. Perform this step to eliminate any possible carryover of RPE buffer. 
13. Elute the RNA using $60 \mu \mathrm{l}$ RNase-free water by centrifuging for 1 min at $\geq 8,000 \times g$.

14. Measure the concentration of RNA using a Thermo Scientific NanoDrop 1000 Spectrophotometer (Table 2). Evaluate the purity of RNA by determining the ratio of absorbance at 260 and $280 \mathrm{~nm}$ and store the samples at $-80^{\circ} \mathrm{C}$ until use. Refer to the flow chart for the main steps (Figure 1).

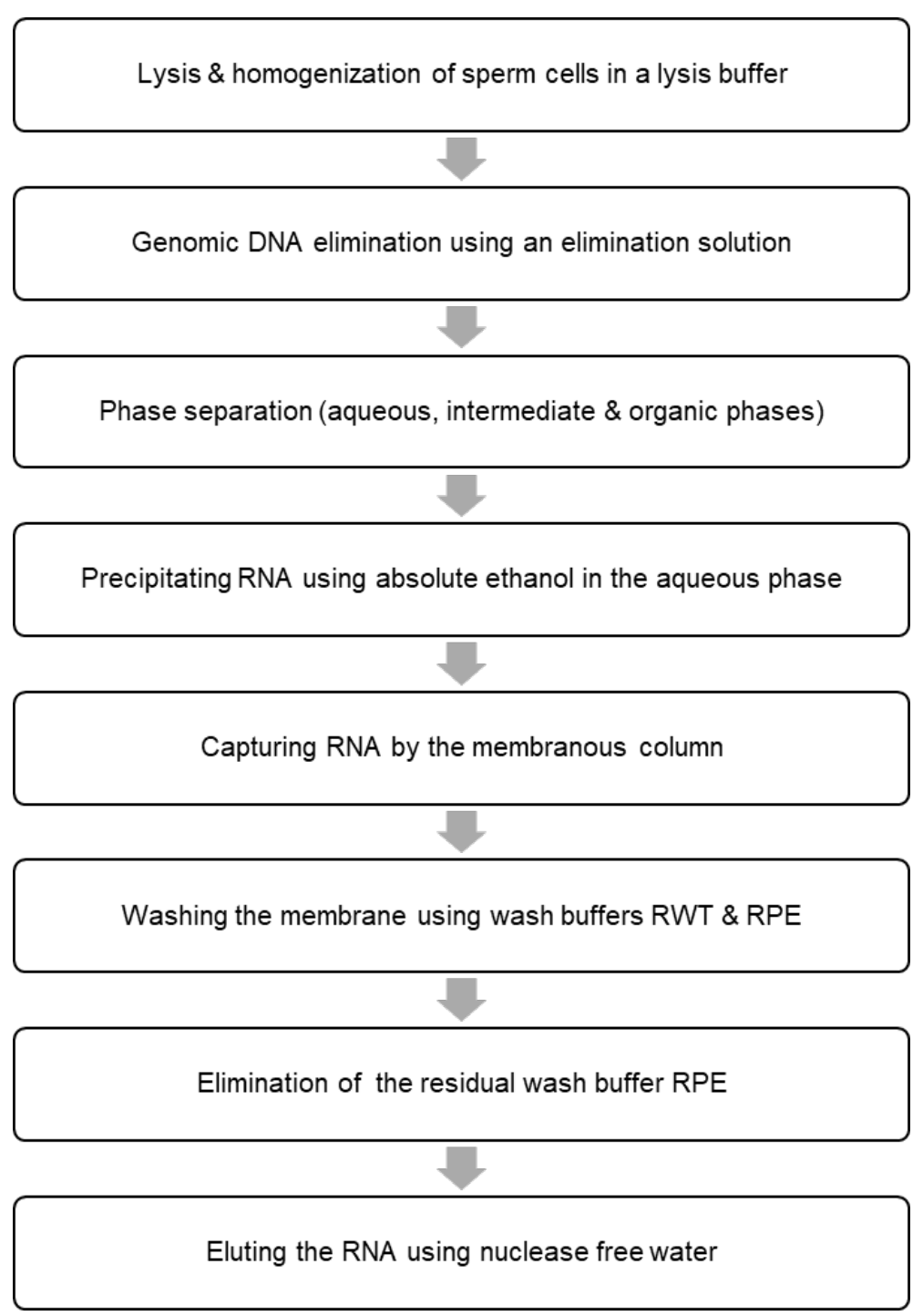

Figure 1. Flow chart for isolating the total RNA including small RNAs from sperm cells 
Table 2. RNA yield from $500 \times 10^{6}$ sperm in ten mature Landrace boars

\begin{tabular}{|l|l|l|}
\hline Landrace Mature Boars & RNA Concentration & RNA Yield in $500 \times 10^{6}$ Sperm \\
\hline Boar 1 & $50 \mathrm{ng} / \mu \mathrm{l}$ & $3,000 \mathrm{ng}$ \\
\hline Boar 2 & $50 \mathrm{ng} / \mu \mathrm{l}$ & $3,000 \mathrm{ng}$ \\
\hline Boar 3 & $60 \mathrm{ng} / \mu \mathrm{l}$ & $3,600 \mathrm{ng}$ \\
\hline Boar 4 & $75 \mathrm{ng} / \mu \mathrm{l}$ & $4,500 \mathrm{ng}$ \\
\hline Boar 5 & $65 \mathrm{ng} / \mu \mathrm{l}$ & $3,900 \mathrm{ng}$ \\
\hline Boar 6 & $60 \mathrm{ng} / \mu \mathrm{l}$ & $3,600 \mathrm{ng}$ \\
\hline Boar 7 & $55 \mathrm{ng} / \mu \mathrm{l}$ & $3,300 \mathrm{ng}$ \\
\hline Boar 8 & $50 \mathrm{ng} / \mu \mathrm{l}$ & $3,000 \mathrm{ng}$ \\
\hline Boar 9 & $70 \mathrm{ng} / \mu \mathrm{l}$ & $4,200 \mathrm{ng}$ \\
\hline Boar 10 & $70 \mathrm{ng} / \mu \mathrm{l}$ & $4,200 \mathrm{ng}$ \\
\hline Mean \pm SD & $60.5 \pm 9.26 \mathrm{ng} / \mu \mathrm{l}$ & $3630 \pm 556 \mathrm{ng}$ \\
\hline
\end{tabular}

D. Seminal plasma RNA isolation

1. Purify total RNA from boar seminal plasma using miRNeasy serum/plasma kit (Qiagen, Valencia, CA, USA).

2. Thaw frozen seminal plasma samples at room temperature until it became completely liquid ( 15 min).

3. Add $750 \mu \mathrm{l}$ of QIAzol reagent (five volumes of seminal plasma) to $150 \mu \mathrm{l}$ of seminal plasma. Mix by pipetting up and down or by vortexing briefly. Incubate for $5 \mathrm{~min}$ at room temperature $\left(15-25^{\circ} \mathrm{C}\right)$.

Note: The lysate can be stored at $-80^{\circ} \mathrm{C}$ for several months.

4. Add $3.5 \mu \mathrm{miRNeasy}$ serum/plasma spike-in-controls (lyophilized C. elegans miR-39 miRNA mimic; $1.6 \times 10^{8}$ copies/ $\mu$ l) and mix thoroughly.

5. Add $150 \mu \mathrm{l}$ chloroform (same volume of starting material). Shake the mixture vigorously for $30 \mathrm{~s}$ and incubate for 2-3 min at room temperature $\left(15-25^{\circ} \mathrm{C}\right)$.

6. Centrifuge at $12,000 \times \mathrm{g}$ for $20 \mathrm{~min}$ at $4{ }^{\circ} \mathrm{C}$. Harvest the upper aqueous phase, avoiding the interphase, into a new Eppendorf tube. Mix with $\sim 1.5$ volumes of $100 \%$ ethanol by pipetting up and down.

7. Transfer approximately half of the mix (about $750 \mu \mathrm{l}$ ) into an RNeasy MinElute spin column in a $2 \mathrm{ml}$ collection tube. Centrifuge at $12,000 \times \mathrm{g}$ for $30 \mathrm{~s}$ at room temperature $\left(15-25^{\circ} \mathrm{C}\right)$.

8. Discard the flow-through and repeat this step with the rest of the sample using the same column.

9. Wash the RNA bound to the membrane sequentially with the buffer RWT and the buffer RPE.

10. Add $700 \mu \mathrm{RWT}$ buffer to the RNeasy MinElute spin column. Close the lid gently and centrifuge for $30 \mathrm{~s}$ at $8,000 \times \mathrm{g}$ at room temperature to wash the column. Discard the flow-through.

11. Pipet $500 \mu \mathrm{l}$ RPE buffer onto the RNeasy MinElute spin column. Close the lid gently and centrifuge for $30 \mathrm{~s}$ at $8,000 \times \mathrm{g}$ at room temperature to wash the column. Discard the flowthrough. 
12. Add $500 \mu \mathrm{l}$ of $80 \%$ ethanol onto the RNeasy MinElute spin column. Close the lid gently and centrifuge for $2 \mathrm{~min}$ at $8,000 \times \mathrm{g}$ at room temperature $\left(15-25^{\circ} \mathrm{C}\right)$ to wash the spin column membrane. Discard the collection tube with the flow-through.

13. Dry the RNeasy MinElute column by centrifugation at $12,000 \times g$ for 5 min and discard the flowthrough and collection tube.

14. Elute RNAs by placing the membrane in $24 \mu \mathrm{l}$ RNase-free water and centrifuging at $12,000 \times \mathrm{g}$ for 2 min.

15. Determine the RNA concentration (Table 3) using a spectrophotometer (Thermo Scientific NanoDrop 1000). Refer to the flow chart for the main steps for isolating RNA from the seminal plasma (Figure 2).

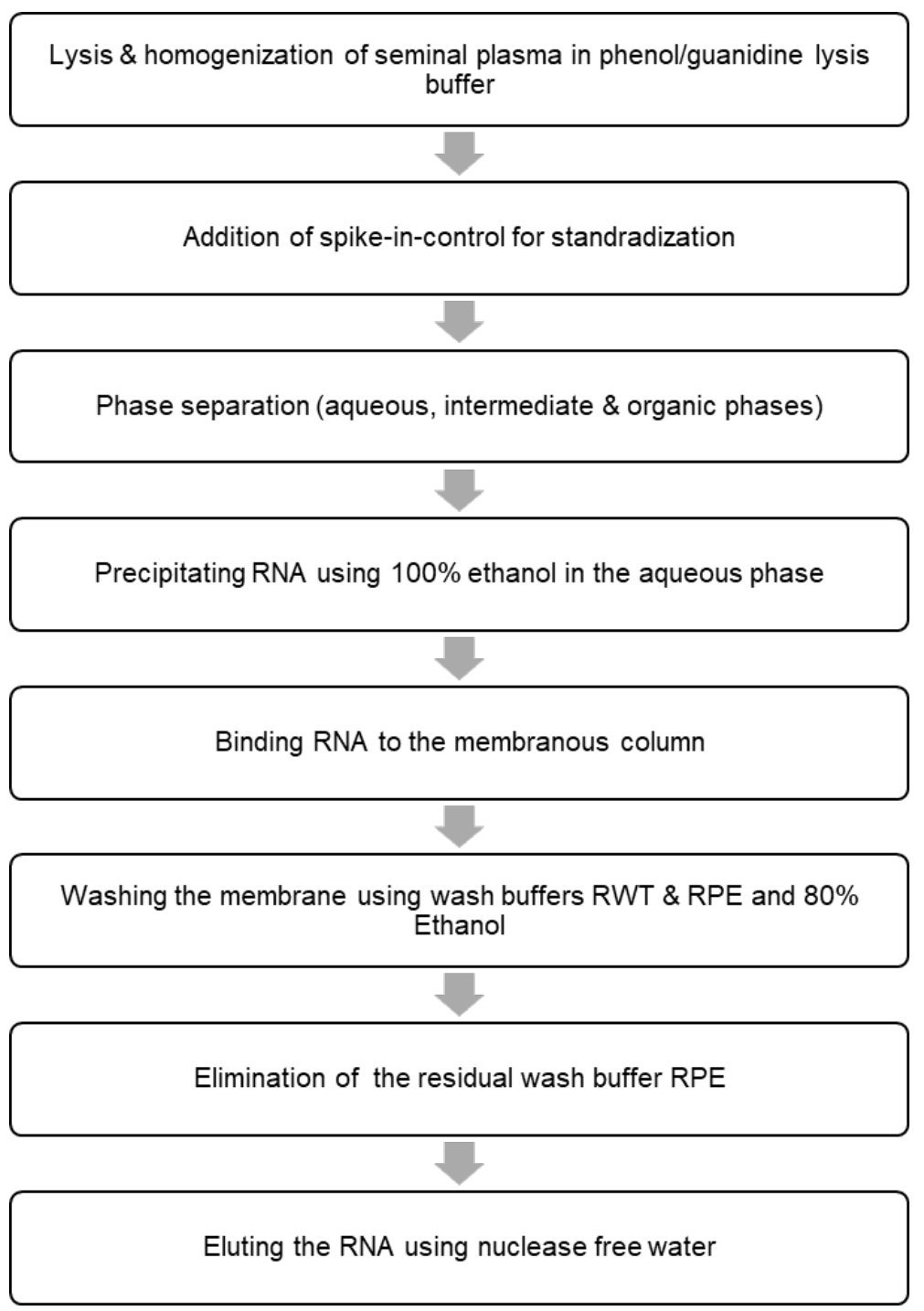

Figure 2. Flow chart for isolating RNA from the seminal plasma 
Table 3. RNA yield from $150 \mu$ of seminal plasma in ten Landrace boars

\begin{tabular}{|l|l|l|}
\hline Landrace Mature Boars & RNA Concentration & Total RNA in $150 \mu$ l Seminal Plasma \\
\hline Boar 1 & $30 \mathrm{ng} / \mu \mathrm{l}$ & $720 \mathrm{ng}$ \\
\hline Boar 2 & $40 \mathrm{ng} / \mu \mathrm{l}$ & $960 \mathrm{ng}$ \\
\hline Boar 3 & $31 \mathrm{ng} / \mu \mathrm{l}$ & $744 \mathrm{ng}$ \\
\hline Boar 4 & $34 \mathrm{ng} / \mu \mathrm{l}$ & $816 \mathrm{ng}$ \\
\hline Boar 5 & $40 \mathrm{ng} / \mu \mathrm{l}$ & $960 \mathrm{ng}$ \\
\hline Boar 6 & $35 \mathrm{ng} / \mu \mathrm{l}$ & $840 \mathrm{ng}$ \\
\hline Boar 7 & $26 \mathrm{ng} / \mu \mathrm{l}$ & $624 \mathrm{ng}$ \\
\hline Boar 8 & $29 \mathrm{ng} / \mu \mathrm{l}$ & $696 \mathrm{ng}$ \\
\hline Boar 9 & $40 \mathrm{ng} / \mu \mathrm{l}$ & $960 \mathrm{ng}$ \\
\hline Boar 10 & $35 \mathrm{ng} / \mu \mathrm{l}$ & $840 \mathrm{ng}$ \\
\hline Mean \pm SD & $34 \pm 4.99 \mathrm{ng} / \mu \mathrm{l}$ & $816 \pm 120 \mathrm{ng}$ \\
\hline
\end{tabular}

\section{Data analysis}

Since this protocol only includes semen volume, sperm concentration, sperm motility, presence/absence of abnormal and immature sperm cells, RNA yield from sperm and seminal plasma from 10 Landrace boars, mean and standard deviation values of the variables are presented in Tables 1, 2 and 3.

\section{Notes}

Diploid spermatogonia differentiate into mature haploid sperm during spermatogenesis in mammals. When haploid spermatids undergo morphological modifications and transition into elongated sperm, transition proteins, protamines and histones play a unique role in condensing spermatid chromatin (Miller et al., 2005). Sperm, in addition to the main contribution of paternal genome, deliver a large range of RNA molecules to the oocyte during fertilization and these RNAs may have a functional role in fertilization and early embryonic development (Boerke et al., 2007; Gòdia et al., 2018). Noncoding RNAs also contributes to fertilization, embryogenesis and offspring health and participate in transgenerational epigenetic inheritance (Champroux et al., 2018). Transcriptional activity is found to be higher in primary spermatocytes and spermatids compared to secondary spermatocytes and then the transcription is almost arrested during the nuclear elongation phase of the final maturation step in spermatogenesis (Dadoune et al., 2004). Presence of coding and non-coding RNAs in sperm has been revealed by a variety of techniques, microarray (Liu, T. et al., 2012; Bansal et al., 2015), qRT-PCR (Kasimanickam and Kastelic, 2016; Kasimanickam et al., 2019a and 2019b) and RNA sequencing (Du et al., 2014; Mao et al., 2014) and these RNAs may originate from germ and somatic cells and partake in a variety of functions.

Sperm transcripts can be used as candidate markers for male fertility. High fertility bulls had higher 
levels of sperm transcripts and their proteins were correlated to important cellular processes such as metabolism, signal transduction, translation, glycosylation, and protein degradation (Lalancette et al., 2008; Kasimanickam et al., 2019a). Five genes, RPL31, PRKCE, PAPSS2, PLP1, and R1G7 were differentially seen between fresh and frozen-thawed sperm in Holstein bulls (Chen et al., 2015). Sperm-borne miRNAs were found to be needed for normal fertilization and preimplantation embryo development in mice (Yuan et al., 2016). Sperm transcripts were associated with in-vitro motility and field fertility in bulls using stringent RNA isolation protocols (Bissonnette et al., 2009; Kasimanickam et al., 2012). A total of 7721 long non-coding RNAs and 6097 mRNAs were found to be differentially expressed in sperm between diabetic and normal group of mice (Jiang et al., 2016). Sperm-borne microRNA-34c was determined to be important for the first cleavage division in mice (Liu, W. M. et al., 2012). A complex population of male-derived small non-coding RNAs were seen in the zygote after fertilization (Krawetz et al., 2011). Since the role of these sperm transcripts is suggested in fertilization as well as zygotic and early embryonic development, a better understanding of these RNAs is imperative. However, the study of sperm RNAs has been challenging because of the difficulty accompanying with sperm RNA isolation. Several sperm RNA isolation protocols have been shown extremely variable sperm RNA yield due not only to the different approaches used but also to the heterogeneity of RNA within an individual sperm (Lalancette et al., 2009; Mao et al., 2013, Mao et al., 2014; Barragan et al., 2015).

Purification of sperm, RNA extraction and evaluation of RNA quality are the critical steps that need to be focused to obtain quality RNA. Besides sperm, an ejaculate also contains somatic cells, including immature germ cells, leucocytes and epithelial cells. Consequently, somatic cell removal is performed to avoid contamination of somatic cell RNAs and to derive only sperm transcripts. However, superior quality semen does not contain either immature germ cells or somatic cells (leucocytes or epithelial cells). Several methods such as swim-up procedure, density gradient centrifugation and lysis protocol are used to remove somatic cells from the ejaculate. Since seminal plasma also contains RNA, complete removal of seminal plasma is furthermore imperative.

To extract RNA from purified sperm, there are two methods primarily being used. One method is based on phase separation and precipitation whereas the other method is dependent on phase separation and column capture of RNAs. Since sperm contains a very small amount of RNA, capturing RNAs by a spin column and then eluting in a small volume of nuclease-free water yield reproducible results in specific to RNA's quantity and quality. Sperm should be devoid of contaminant of somatic cells such as leukocytes and epithelial cells. Semen collected from mature and healthy domestic animals does not generally contain somatic cells. Presence of somatic cells can be evaluated by microscopic examination. RNA's quantity and quality can be determined using a NanoDrop spectrophotometer (Fisher Thermo Scientific, Bothell, WA, USA) or an Agilent BioAnalyzer (Agilent Technologies, Santa Clara, CA, USA). Sperm does not contain ribosomal RNAs, $18 S$ and 28 S ribosomal subunits (Goodrich et al., 2013) in contrast to other types of cells. The absence of these ribosomal RNAs in the elute can validate the purity of sperm RNAs.

Messenger RNAs have been found in mature sperm in different animal species. Transcriptome 
analysis of ejaculated sperm has been performed in pigs, many mRNAs have been identified in sperm, and these mRNAs have been associated with biological processes, molecular functions and cellular components of spermatogenesis and other testicular functions (Yang et al., 2009). Various sperm transcripts at different expression levels have been noticed between capacitated and noncapacitated sperm and variation in mRNAs level in sperm caused different cleavage rate in pigs (Hwang et al., 2013). Sperm containing abundant levels of MYC, CYP19, ADAM2, PRM1 and PRM2 instigated the increased cleavage rate. Often physical stress, environmental stress and infections affect the boar semen quality. In addition to the conventional semen parameters, sperm transcriptomics could serve as a reliable biomarker to evaluate sperm quality and fertility. Sperm delivers not only DNA to the oocyte but also bring thousands of RNAs to the oocyte, and these coding and non-coding RNA species greatly influence gene regulation in developing embryos for efficient implantation and placental development. Although small quantity of RNA is detected in seminal plasma when compared to sperm RNA in each semen sample (Kasimanickam et al., 2019b), comparative analysis of expression levels will be crucial to elucidate their functional significance and mechanistic interpretation of cell to cell communication and shuttling between endogenous and exogenous environment.

Therefore, efficient methods of sperm purification, RNA extraction from sperm and characterizing RNA's quality are essential to elucidate their clinical significance. In this protocol, details procedures for the separation of pure sperm population and seminal plasma from high-quality semen via washing steps, extraction of measurable quantities of sperm and seminal plasma RNAs using membrane column capturing and determining the quantity and quality are presented. The outcome of these procedures appears to be reproducible for different boars. In summary, these techniques can be repeated for superior quality semen to obtain a detectable amount of good quality sperm and seminal plasma RNAs to utilize for downstream applications (Figure 3). 


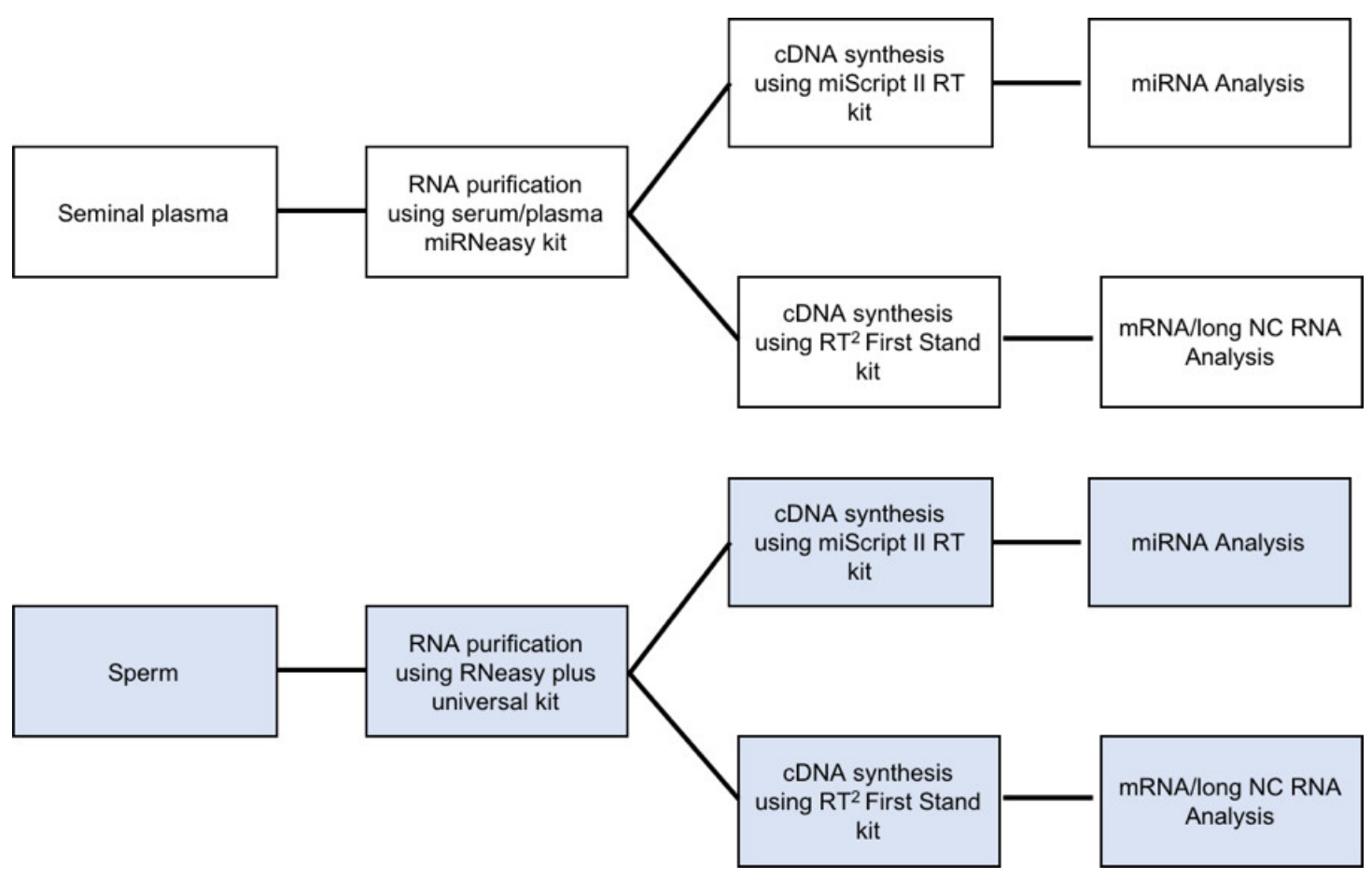

Figure 3. Flow charts showing the use of sperm and seminal plasma RNA in downstream experiments

\section{Critical parameter and troubleshooting:}

Although high quality ejaculated semen from superior genetics mature boars are devoid of somatic cells such as leukocytes and epithelial cells, many semen samples including samples with the history of infertility have a significant number of immature germ cells, somatic cells and bacteria. Removal of somatic and immature cells is critical to prevent the contamination of RNA from these immature, epithelial, inflammatory and bacterial cells. In those circumstances, density gradient separation technique, somatic cell lysis strategy, and swim-up protocol can be performed to purify mature sperm. For instance, discontinuous Percoll (90\% and 45\% Percoll layers) gradient separation of pure sperm can be employed and selection of these procedures is based on the subsequent application of the study. Swim-up protocol is better for the in-vitro fertilization and the follow-up transcriptome analysis whereas Percoll gradient separation is appropriate for a transcriptome study to determine the sperm quality. Since sperm contains very scanty amount of RNA, total sperm RNA can be captured by a membranous column and subsequently the RNA can be eluted in a small volume of nuclease-free water. When the small volume elution is difficult, a larger volume of nuclease-free water can be used to elute the RNA and subsequently the diluted samples can be concentrated using an RNA concentration protocol. RNAs dissociate into the aqueous phase and hence phase separation is critical. The phase separation should be carefully performed not touching the interphase. When the quantity and purity of the RNA are evaluated using NanoDrop spectrophotometer, the ratio of absorbance at 260 and $280 \mathrm{~nm}$ wavelength should be close to 2.0. A small change in $\mathrm{pH}$ can overestimate/underestimate the ratio. If the results are not reproducible, another type of spectrophotometer can be used to evaluate the quality. The 
absorbance spectral graph should be ideal and should indicate the perfect 260/280 ratio.

Superior genetics mature boars produce $100-250 \mathrm{ml}$ of sperm-rich fraction. Semen can be collected thrice weekly for an optimal quantity and quality. Concentration can range from 0.7 to 2 billion sperm $/ \mathrm{ml}$ based on the secretions of accessory glands. Sperm motility varies from $80 \%$ to $90 \%$. A total of 500 million sperm yield RNA ranging from $3,000 \mathrm{ng}$ to $4,500 \mathrm{ng}$. The ratio of absorbance at $260 / 280 \mathrm{~nm}$ wavelength ranges from 1.92 to 2.08 . RNA yield from $150 \mu \mathrm{l}$ of seminal plasma varies from $720 \mathrm{ng}$ to $960 \mathrm{ng}$ whereas the purity ranges from 1.92 to 2.08 .

Semen collection, separation and purification of sperm and seminal plasma, total RNA extraction and characterization can be performed in two weeks for ten boars, provided trained mature boars for semen collection, other supplies, equipment for laboratory work and personnel are available.

\section{Acknowledgments}

This detailed protocol presented here is expanded from our publications, Kasimanickam and Kastelic (2016) and Kasimanickam et al. (2019b).

\section{Competing interests}

The authors declare no competing interests.

\section{Ethics}

This study protocol strictly followed the standard ethics and use of animal cells for research. The protocol was approved by the institutional animal care and use committee of Washington State University (Protocol Number: 04070-001).

\section{References}

1. Bansal, S. K., Gupta, N., Sankhwar, S. N. and Rajender, S. (2015). Differential genes expression between fertile and infertile spermatozoa revealed by transcriptome analysis. PLOS One 10(5): e0127007.

2. Barragan, M., Martinez, A., Llonch, S., Pujol, A., Vernaeve, V. and Vassena, R. (2015). Effect of ribonucleic acid (RNA) isolation methods on putative reference genes messenger RNA abundance in human spermatozoa. Andrology 3(4): 797-804.

3. Bissonnette, N., Levesque-Sergerie, J. P., Thibault, C. and Boissonneault, G. (2009). Spermatozoal transcriptome profiling for bull sperm motility: a potential tool to evaluate semen quality. Reproduction 138(1): 65-80.

4. Boerke, A., Dieleman, S. J. and Gadella, B. M. (2007). A possible role for sperm RNA in early embryo development. Theriogenology 68 Suppl 1: S147-155. 
5. Champroux, A., Cocquet, J., Henry-Berger, J., Drevet, J. R. and Kocer, A. (2018). A decade of exploring the mammalian sperm epigenome: paternal epigenetic and transgenerational inheritance. Front Cell Dev Biol 6: 50.

6. Chen, X., Wang, Y., Zhu, H., Hao, H., Zhao, X., Qin, T. and Wang, D. (2015). Comparative transcript profiling of gene expression of fresh and frozen-thawed bull sperm. Theriogenology 83(4): 504-511.

7. Dadoune, J. P., Siffroi, J. P. and Alfonsi, M. F. (2004). Transcription in haploid male germ cells. Int Rev Cytol 237: 1-56.

8. Du, Y., Wang, X., Wang, B., Chen, W., He, R., Zhang, L., Xing, X., Su, J., Wang, Y. and Zhang, $Y$. (2014). Deep sequencing analysis of microRNAs in bovine sperm. Mol Reprod Dev 81(11): 1042-1052.

9. Gòdia, M., Swanson, G. and Krawetz, S. A. (2018). A history of why fathers' RNA matters. Biol Reprod 99(1): 147-159.

10. Goodrich, R. J., Anton, E. and Krawetz, S. A. (2013). Isolating mRNA and small noncoding RNAs from human sperm. Methods Mol Biol 927: 385-396.

11. Hwang, J. Y., Mulligan, B. P., Kim, H. M., Yang, B. C. and Lee, C. K. (2013). Quantitative analysis of sperm mRNA in the pig: relationship with early embryo development and capacitation. Reprod Fertil Dev 25(5): 807-817.

12. Jiang, G. J., Zhang, T., An, T., Zhao, D. D., Yang, X. Y., Zhang, D. W., Zhang, Y., Mu, Q. Q., Yu, N., Ma, X. S. and Gao, S. H. (2016). Differential expression of long noncoding RNAs between sperm samples from diabetic and non-diabetic mice. PLoS One 11(4): e0154028.

13. Kasimanickam, R. K., Kasimanickam, V. R., Arangasamy, A. and Kastelic, J. P. (2019a). Sperm and seminal plasma proteomics of high- versus low-fertility Holstein bulls. Theriogenology 126 : 41-48.

14. Kasimanickam, V. and Kastelic, J. (2016). MicroRNA in sperm from Duroc, Landrace and Yorkshire boars. Sci Rep 6: 32954.

15. Kasimanickam, V., Buhr, M. and Kasimanickam, R. (2019b). Patterns of expression of sperm and seminal plasma microRNAs in boar semen. Theriogenology 125: 87-92.

16. Kasimanickam, V., Kasimanickam, R., Arangasamy, A., Saberivand, A., Stevenson, J. S. and Kastelic, J. P. (2012). Association between mRNA abundance of functional sperm function proteins and fertility of Holstein bulls. Theriogenology 78(9): 2007-2019 e2002.

17. Krawetz, S. A., Kruger, A., Lalancette, C., Tagett, R., Anton, E., Draghici, S. and Diamond, M. P. (2011). A survey of small RNAs in human sperm. Hum Reprod 26(12): 3401-3412.

18. Lalancette, C., Platts, A. E., Johnson, G. D., Emery, B. R., Carrell, D. T. and Krawetz, S. A. (2009). Identification of human sperm transcripts as candidate markers of male fertility. $J$ Mol Med (Berl) 87(7): 735-748.

19. Lalancette, C., Thibault, C., Bachand, I., Caron, N. and Bissonnette, N. (2008). Transcriptome analysis of bull semen with extreme nonreturn rate: use of suppression-subtractive hybridization to identify functional markers for fertility. Biol Reprod 78(4): 618-635. 
20. Liu, T., Cheng, W., Gao, Y., Wang, H. and Liu, Z. (2012). Microarray analysis of microRNA expression patterns in the semen of infertile men with semen abnormalities. Mol Med Rep 6(3): 535-542.

21. Liu, W. M., Pang, R. T., Chiu, P. C., Wong, B. P., Lao, K., Lee, K. F. and Yeung, W. S. (2012). Sperm-borne microRNA-34c is required for the first cleavage division in mouse. Proc Natl Acad Sci U S A 109(2): 490-494.

22. Mao, S., Goodrich, R. J., Hauser, R., Schrader, S. M., Chen, Z. and Krawetz, S. A. (2013). Evaluation of the effectiveness of semen storage and sperm purification methods for spermatozoa transcript profiling. Syst Biol Reprod Med 59(5): 287-295.

23. Mao, S., Sendler, E., Goodrich, R. J., Hauser, R. and Krawetz, S. A. (2014). A comparison of sperm RNA-seq methods. Syst Biol Reprod Med 60(5): 308-315.

24. Miller, D., Ostermeier, G. C. and Krawetz, S. A. (2005). The controversy, potential and roles of spermatozoal RNA. Trends Mol Med 11(4): 156-163.

25. Ostermeier, G. C., Dix, D. J., Miller, D., Khatri, P. and Krawetz, S. A. (2002). Spermatozoal RNA profiles of normal fertile men. Lancet 360(9335): 772-777.

26. Yang, C. C., Lin, Y. S., Hsu, C. C., Wu, S. C., Lin, E. C. and Cheng, W. T. (2009). Identification and sequencing of remnant messenger RNAs found in domestic swine (Sus scrofa) fresh ejaculated spermatozoa. Anim Reprod Sci 113(1-4): 143-155.

27. Yuan, S., Schuster, A., Tang, C., Yu, T., Ortogero, N., Bao, J., Zheng, H. and Yan, W. (2016). Sperm-borne miRNAs and endo-siRNAs are important for fertilization and preimplantation embryonic development. Development 143(4): 635-647. 